\title{
The drama of resilience: learning, doing, and sharing for sustainability
}

\author{
Katrina Brown $^{1}$, Natalia Eernstman $^{2}$, Alexander R. Huke $^{3}$ and Nick Reding ${ }^{4}$
}

\begin{abstract}
We discuss the use of participatory drama and transformative theatre to understand the sources of risk and resilience with coastal communities. We analyze and describe two performances developed as part of a project exploring people's resilience to extreme weather events and to coastal dynamics in the face of climate change. We examine the process of devising the performance, which used various elicitation techniques to examine what matters to people in times of change and how people are able to respond to changes now and in the future. We discuss how creative practices such as participatory drama may contribute to the understanding of resilience, challenge assumptions, and bring new perspectives. Finally, we discuss how participatory drama informs action- and solutionsoriented work around resilience, poverty, and change.
\end{abstract}

Key Words: climate change; coastal communities; forum theatre; participatory drama

\section{INTRODUCTION}

This research is situated at the interface between social science and theatre-based artistic practice. We used performative methods to explore the concept of resilience and devise an intervention that aims to empower, give voice, find solutions, and support social action. We first describe the field of art-science collaborations (why and how), and then present relevant performative terms that will be used to present and discuss the cases. We then introduce the context of this work, and the project, "You, me, and our resilience".

\section{Art-science collaborations}

Many scholars, and indeed research funders, now emphasise the need for "transformative" social science to address major global challenges such as rapid climate change, growing inequality, resource scarcity, and financial instability. In a seemingly increasingly complex world, commentators specifically point to the limitations of existing epistemologies and methods to address these challenges. They emphasize the need for a different type of science that may be more capable of tackling contemporary complex social-environmental issues (Funtowicz and Ravetz 1993, Cherry 2005, Seeley and Reason 2008, Gray et al. 2011). Law (2004) argues that social science is in need of innovation. In his view, the world is "vague, diffuse or unspecific, slippery, emotional, ephemeral, elusive or indistinct [and] changes like a kaleidoscope" (Law 2004:2). Conventional social science often fails to capture these realities and often relies on simple, clear-cut, and linear truths.

In this context, the arts are often suggested as a viable alternative to conventional and extractivist social science. The biologist Everden, for example, reminds us that "environmentalism involves the perception of values, and values are the coin of arts" (Everden quoted in Arons and May 2012:2). Szerszynski and colleagues (Szerszynski 2003, Szerszynski et al. 2003) make the case that the world, life, and human relationships with nature are essentially fluctuating, complex, and improvised. Subsequently, social-ecological dynamics are poorly understood through a "positivist version of the world" (Szerszynski et al. 2003:12). Such realities, they argue, are better captured through a performative approach in which knowledge exists within processes of agency with and in the world.
Collaborative projects between artists and scientists are not new. There are many examples of visual artists engaging with data of mathematicians or physicists, visualising some of the complex outcomes that the research produces. There is an increasing demand for artists to work with climate scientists, for example. In some instances, scientists employ artists to translate difficult or "dull" material and inconvenient questions around climate change into engaging means that more effectively reach a target audience. However, the collaboration in these instances often does not exceed the level of art being used to explain or communicate certain scientific results to an audience. According to Ede (2005:3), the arts are seen as prettification to enhance the public understanding of science. Similarly, the influence of the sciences on the arts is often restricted to the artist using certain scientific data or ideas as inspiration or content for the creation of artwork, which is subsequently displayed in an "arts environment" such as a gallery. Such collaborations are valuable in their own right but arguably underuse the arts to address and possibly resolve "wicked problems" in truly novel ways. For social scientists to reinvent their practice in ways that both Law and Szerszynski advocate, the collaboration has to reach a level at which artist and scientist engage in uncomfortable conversations through which they both shift their epistemological and ontological presumptions.

The cases described herein aimed to surpass the communicative potential of the arts. They employed performance methods to research and operationalize the concept of resilience at a community level. Instead of using the arts as a means to transmit scientifically preconceived messages to a target audience, artistic methods were used to explore what resilience means to people and how it can be fostered. Whether and how the arts indeed shed new light on the concept of resilience is the focal point of our study. However, before that question is addressed, we delineate the field of artistic performance in which the research took place.

Theatre in relation to ecology and community resilience Artists do not operate in isolation (as is sometimes assumed), creating works of art that have no relevance to the more worldly matters with which scientists engage. There are a growing number of artists who make work that responds to social and environmental issues and address questions similar to the ones with which scientists grapple. 
Leaving aside (but certainly not disregarding) a large body of work labelled as "eco-art" (see for example, Adams 2002 and Berleant 2002) and "socially engaged practice" (Bishop 2012), we focus on the field of applied, community, participatory, or sitespecific theatre, in which the two cases we describe took place. The value of these practices in relation to community development is described by Heras and Tàbara (2014) in a useful overview of theatre-based participatory tools directed at social change. They define applied theatre as "those dramaturgic activities, primarily carried out outside ordinary theatre institutions specifically intended to benefit individuals, communities and societies who perform them" (Heras and Tàbara 2014:380). These performances are often devised in close collaboration with the communities that they target, employing a range of theatre-based research methods that elicit local knowledge and reveal people's stories or experience of a certain issue. For example, "Theatre for Development" has the imperative to empower marginalized people (Boon and Plastow 2004) by focusing on the stories and realities of "largely silent (or silenced) groups of people" (Van Erven 2001:3). "Community theatre" is a broader term that covers practices in which local performers and amateur artists collectively shape a piece alongside professional performers and directors.

A feature that these applied theatre practices have in common, Heras and Tàbara (2014) argue, is that the pieces are not used as a means to instrumentally teach something but rather as ways of exploration, questioning, and solution-finding. The practices "explicitly attempt to be goal searching instead of goal achieving" (Heras and Tàbara 2014:382). The goal is framed through the process of doing the practice; it is not determined in advance. The goal is collectively created as an outcome of the interaction between artists and participants.

S.A.F.E. Kenya, one of the two theatre groups that were part of this research, predominantly uses an applied theatre form called "forum theatre." To devise a forum play, professional actors often work alongside community members, exploring a particular issue that is alive for that community. The performance is then designed to ask questions of its (community) audience members, who are invited to respond and cocreate solutions to the presented issue. Instead of performing a show in front of a passive audience, the interactive nature of a piece invites people to come up with their own solutions and "practice for reality," thereby changing them from subjects of social-environmental conditions into active agents that contribute to the creation of knowledge around and with their environments.

The piece developed in Cornwall, UK as part of this research can be seen as a form of applied theatre but also crosses over into a field of practice termed "site-specific theatre." In this discipline, the focus is less on the transformative or empowering aspect of the work and more on the manner in which a theatre piece is devised at and from a specific place. These performances often take place outdoors, for example, in villages, woods, or abandoned buildings, so rather than being an indoor theatre piece that is staged at a random site outside of the established theatre, the piece reveals the "layers of a site" (Wilkie 2002:150) through a range of references found at the site, e.g., historical documentation, myths, objects, texts, sounds, smells, and past and present usage. Pearson (2010) describes such devising process as archaeology: a process of excavating the contemporary past while cultivating "a renewed sensitivity to the fabric of the present and attention to those details distinct and differentiated that signal our presence, but that we consciously disattend or casually ignore or commit to collective amnesia" (Pearson 2010:43). Excavation methods unearth, bring to the forefront, and amplify layers of human narratives of a place, which then feed into the creation of a piece that is staged at the location in question. The process of devising is described next.

\section{"You, me, and our resilience"}

The activities reported here were undertaken as part of the project, "You, me, and our resilience." This project, funded by the AXA Research Fund as an Outlook project (see http://www.exeter.ac. uk/esi/research/youmeourresilience/), is primarily concerned with public engagement and explores diverse framings and understandings of resilience through participatory drama. It has three principles at its core: (1) cross-cultural learning based on narratives and lived experiences of resilience to multiple hazards, (2) using participatory theatre as a means to empower communities to transform their circumstances, and (3) furthering engagement with scientists, policy makers, and insurance sectors. We sought to use applied theatre to explore resilience as experienced and understood by different communities and cultures, and to prompt a dialogue between and across different communities and stakeholders, including scientists, risk analysts, performers, and different government agencies and nongovernmental organizations. We worked with two groups who specialize in creative practice, community theatre, and social action: S.A.F.E. Kenya (http://safekenya.org/), from Mombasa, Kenya; and Golden Tree Productions (http://goldentree.org.uk/), from Cornwall, in southwest UK. We next describe the process of creating performances in the two countries. The aim was to facilitate cross-cultural dialogue and learning, not to duplicate activities or compare and contrast. The activities developed or evolved in an organic or adaptive way, closely linked to the local context and in response to community insights and issues, rather than in a top-down, predefined or prescriptive way. This enabled performers to propose and develop the best activities to represent and present the issues and concerns identified by each community.

The project is undertaken in very different communities in Kenya and the UK. However, these physically unconnected communities are inextricably linked through their shared experiences and vulnerabilities to environmental change. Working with the two identified theatre groups, necessarily different but similar, productions were developed in direct response to recent environmental events and the lived experiences of communities as they wrestle, respond, and react to the relative socioeconomic and social-ecological challenges they face.

In light of the very different cultural and development profiles of the target communities, S.A.F.E Kenya and Golden Tree Productions devised productions that sought to engage their audiences and participants in distinct and nuanced ways. S.A.F. E Kenya's production focused on solutions that individuals and communities could coalesce around in response to a fictitious storm event, whereas Golden Tree Productions developed a production directly resonating with a recent severe coastal storm event and sought to explore the complex social responses to loss in the light of a changing environment. 
Fig. 1. Timeline and processes involved in devising, performing, and evaluating the theatre productions.

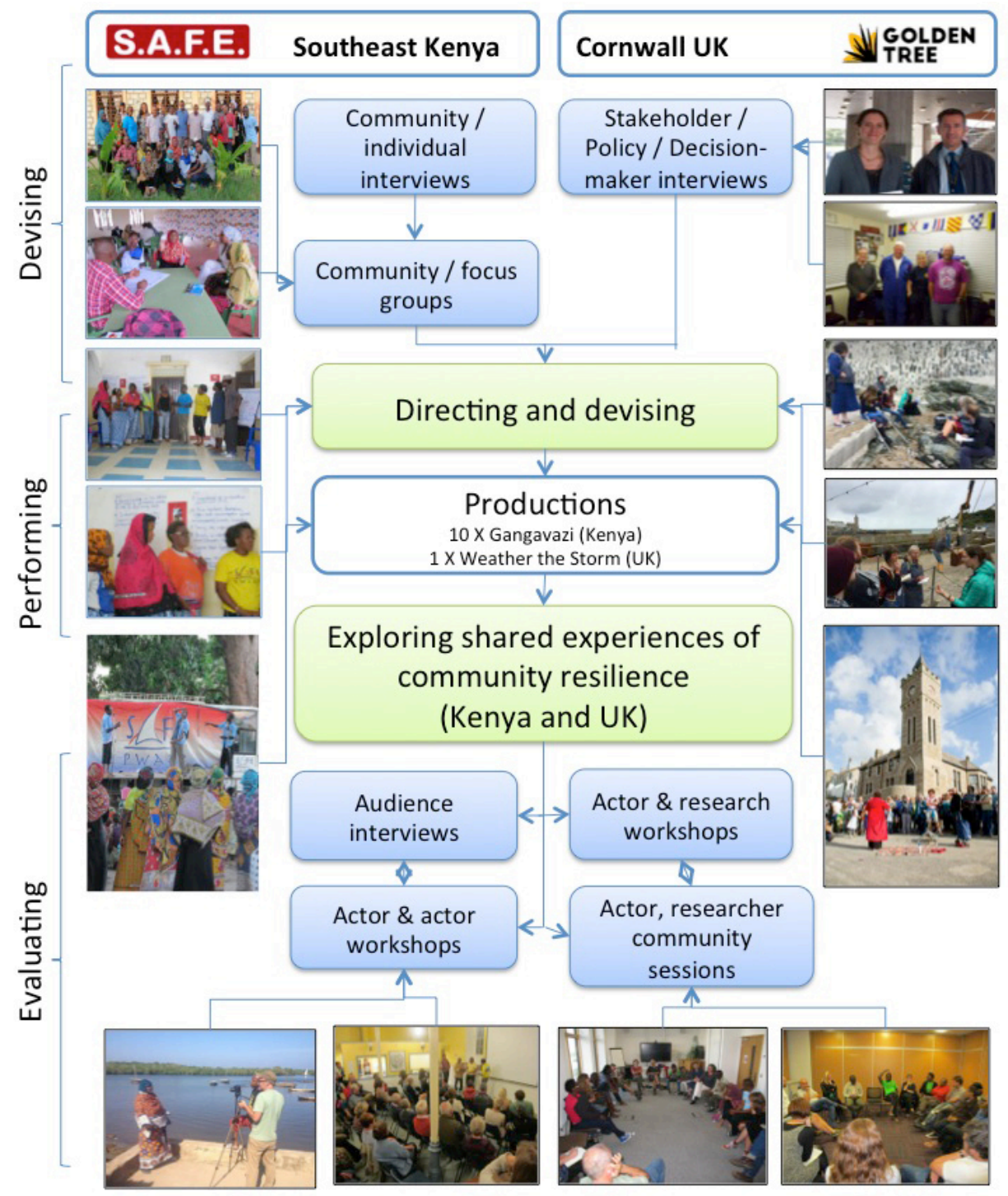

\section{THE PROCESS}

The coastal villages of Vanga and Gazi in southeast Kenya and the coastal town of Porthleven in southwest UK were the key focal points for production and project activity. Coastal proximity, rurality, and changing economies and demographics alongside the need to mitigate and build resilience to a changing environment were key areas of similarity between these physically unconnected communities. Both production companies have a track record and connections with the communities, thus supporting early-stage project engagement and activities.

In both Kenya and UK, initial work involved gaining a better understanding of risk perceptions and priorities within the communities and understanding where environmental and weather-related risks sat within personal risk landscapes. A series of interviews were undertaken with individuals in each context.
This initial gathering of data was then developed further through focus groups, workshops, and in-depth unstructured interviews with residents and key local stakeholders, decision makers, and partners. The production companies used these data, i.e., the transcripts from interviews and focus groups, to develop a production from the gathered lived experiences and narratives (Fig. 1).

S.A.F.E Kenya's production, Gangavazi, involved a number of fictional characters inspired from the focus groups made up of farmers, fishers, and their families, alongside chiefs, teachers, and government advisors. Throughout the production, the story shows how the individuals' lives are affected and are dependent ecologically, socially, and economically on a changing and increasingly volatile environment. In the space of the 45-min play, issues such as sustainable fishing, mangrove cutting and planting, 
economic diversification and local supply chains, fuel management, sustainable farming, and biodiversity enhancement were all touched on, alongside more cross-cutting issues of community governance and planning. The play ends with a weather-related catastrophe in which a number of key characters lose their lives. The audience is then asked, "What could they have done differently?" There is then a facilitated discussion about what the play's characters and community could have done differently to mitigate this tragedy and other problems highlighted in the play. After further discussion, an alternative ending is then acted out, articulating a happier ending for the play's characters and a more resilient community.

The production was performed in 10 different coastal communities in southeast Kenya, engaging over 4700 people. Several days after the production, hosting villages were revisited by S.A.F.E Kenya, seeking feedback from audience members regarding their observations and key messages derived from the production. Thus, as one audience member remarked: "The community members got to share their opinions about different challenges they were facing and others came up with very good solutions for them."

In the UK, Golden Tree Productions undertook a singleperformance production, Weather the Storm, in the coastal town of Porthleven. As in Kenya, the production was devised in direct response to information gathered by the actors' interviews with key community members, stakeholders, and decision makers who had been affected or involved in response to a severe coastal storm event in early 2014. The performance followed a form of applied, site-specific theatre, taking the invited audience from a pub-quiz (a traditional form of entertainment held in a public house or bar: https://en.wikipedia.org/wiki/Pub quiz) to experience the dramatic events at Seaview Terrace, a fictional street close to the shoreline, where homes were flooded and residents were evacuated during a violent storm. Exploring loss and grief associated with extreme weather, the piece involved singing by Porthleven Fishermen's Choir, and the participation of fishers, coastguards, publicans, and other local residents and stakeholders. The production engaged the audience with a range of emotions, highlighting some of the dilemmas surrounding coastal defence, for example, where to draw the line, and the multiple strands and stressors, and possible futures for coastal communities in times of rapid change. The production was designed primarily as a way of creating space for a conversation about these issues.

Weather the Storm engaged 215 people in the single-performance production and the devising process leading up to the final production. Following the performance, informal interviews were undertaken with audience members asking them about their most memorable moments, their understanding of community resilience, and opportunities for future action. These interviews revealed key insights on the severity of storms and on the sense of shared experience and empathy the production evoked. For example, participants stated, "What it really illustrated to me was the futile energy of trying to hold the sea back and the scale to which we are trying to operate on," and, "We were all part of it and being face to face with people that were losing their properties."

After the Porthleven event, which seven members of S.A.F.E. Kenya who had been involved in Gangavasi attended, a series of reflexive workshops were convened over a three-day period. The first involved the performers, devisers, and research team in the "You, me, and our resilience" project. In this workshop, participants reflected on the process, prompted by a series of questions: What did we do and why? What did we learn? What do we do next? The second workshop was with the same group and was extended to include a wider group of researchers studying coastal change and resilience. It focused on some broader questions, including: What do we know about coastal communities and change? What can we learn from different methods? What is the role of theatre and creative processes in research? What difference does it make? How does it potentially change our research and our roles as researchers? The third workshop extended the group to include key stakeholders. It included a more formal presentation and a seminar with postgraduate students. Most of the following discussion is based on this reflexive evaluation process.

\section{DISCUSSION}

Here, we reflect on what we learned about resilience from these activities. In other words, what new insights and knowledge were gained as outcomes of the work? What did we learn about the process of doing research? What did we learn about novel dimensions that performative approaches bring to collaborative and collective work?

\section{Reflections on resilience: "There's nothing like the power of the sea"}

Here, we focus primarily on what we were able to learn about resilience and our reflections on it. Four themes emerged from the interviews and discussions with communities and stakeholders, and between actors and researchers, that preceded the performances, and from the reflexive and interpretive evaluations of the performances. The first theme concerns the dynamic nature of change, and people's attitudes to it; the second theme concerns how resilience is characterised in Cornwall and Kenya; the third theme concerns the narratives and solutions that were developed; and the fourth theme concerns the similarities across the two different contexts.

First, there was a strong narrative about environmental and social dynamics and how everything changes. In both Kenya and Cornwall, sea and land are the basis for everything, but both are changing. People identified weather and climate as part of the changes that they observed and experienced, and they especially emphasized the power of the sea and people's helplessness in the face of it. Storms are an accepted part of life at the coast, but in Kenya, people asked, "Are we cursed?" in the face of these changes. In Cornwall, one interviewee remarked, "There's nothing like the power of the sea." This quotation was used to frame the short video about the performance (https://vimeo. com/145053104).

Second, there was much reflection on resilience, who is more resilient than whom, and the shape and nature of resilience. For example, on the surface, Cornish communities might be assumed to be more resilient than Kenyan coastal communities, who are described as marginal and living precarious lives, but as Will, the Artistic Director of Golden Tree Productions said, "So much resonates." The different dimensions of resilience were explored by the actors. Although communities in Kenya are much poorer 
and have very few livelihood options, declining resources (land, fish), and less support from government, in some respects, people are resilient: they can fall back on their own resources in times of need and do not expect external support. In contrast, communities in Cornwall are much more dependent on outside help. In general, they do not produce their own food or energy, and in times of emergency, they demand external help. In relating these ideas to literature on community resilience, it becomes evident that resilience is framed, constructed, and perceived quite differently. In Kenya, there is high social capital; in Cornwall, there are much higher levels of assets and infrastructure. However, in both contexts, there is low self-efficacy, articulated and manifest in quite different ways. This corresponds to literature on community resilience (Brown and Westaway 2011, Berkes and Ross 2014) and adaptive capacity (Eakin et al. 2015) that identifies self-efficacy as a key component of adaptive capacity.

One aspect of resilience emphasized in both processes was connectivity and interconnections. In particular, it was observed that in Cornwall, people are disconnected from their community and especially from the sources of food, water, and energy, which are provided for them by outside organizations. In Kenya, however, people are much more connected to sources of food, water, and energy, and to the environment more generally. This relates to dependency and sensitivity in both positive and negative ways. For example, in Cornwall, people are dependent on supermarkets for food, rather than directly dependent on the sea or the land. Dependency (Adger 2000) and sensitivity (Cinner et al 2012) have been identified in previous studies as important in determining the capacity to deal with climate and other changes.

In each context, the issue of agency was important but was articulated in slightly different terms. In Cornwall, it was about who protects whom and from what, i.e., about how the state or local government have a duty of care, or a statutory responsibility for protecting its citizens. In Kenya, it was more about the need for community voice and empowerment to be able to demand resources and services from the state. Agency is clearly significant for how people identify potential solutions or needs to build resilience and in conferring capacity (Brown 2016).

Third, the performances presented and told people's own stories and their emotional and often conflicted views of change. The Kenyan production was very much focused on finding solutions with people, which is a more "classic" form of forum theatre. The strength of the production, which was stated a number of times, is in telling people's own stories, in narrating the experiences of villagers that they recognize and that uses their own language and terms. The solutions come from the community itself, who identifies and finds the solutions through the performance.

Two key points were emphasized in discussions about the performances in Kenya. First, access to land for farming is vital for livelihood security. Second, the lack of unity in communities is seen as an impediment to dealing with a range of different changes or stressors. Discussions identified that the community needs cohesion to come together to demand support, i.e., only when people have one voice can they be heard. In addition, destructive environmental practices such as dynamite fishing and mangrove and tree cutting were also mentioned as making people more vulnerable and impoverishing future generations.
In Cornwall, the emphasis was slightly different: Will from Golden Tree Productions sees empowerment as an important outcome of the work, but it is more about individual empowerment perhaps than community voice. He explained how local community members who were involved and participated in the production, for example, the choir members, fishers, coastguard, and even the baker, were a "very positive part of the project" and that incorporating them in roles they felt comfortable with (i.e., performing tasks they were familiar with) was really key to successful engagement. However, although the productions gave different emphasis to finding solutions, the overall effect of both was to open up a means of engagement and find space to talk about coastal change and resilience between sets of people who under normal circumstances might not discuss these issues.

\section{Reflections on the process}

The process developed as an adaptive process, and although we aimed to find out about people's capacity to respond to extreme weather events, we wanted to place this within the context of other changes and other stresses experienced by coastal communities where we worked. The work is emphatically place based and context specific. The process, the performances, the stories they told, and the design are determined by the events, issues, and concerns of the communities themselves. We could not take the play developed in Kenya and just remake it in Cornwall. The strength of the performance and its impact rests on telling the stories of those people and those places. This is clearly very different to how we usually (but not always) do research, where researchers often determine the priorities and predesign the process of inquiry. This has two important implications. First, for us as researchers, it means a shift in power relations whereby the participants become more instrumental in shaping the process. Second, the performance becomes powerful because it tells the participants' stories. In the UK, people might go to the theatre, but they are normally passive members of the audience hearing someone else's words and story. In Kenya, plays are rarely available to rural villagers, and television dramas depict urban life (at best) and international elites (at worse). A story told in local languages uses participants' voices, draws the participants in, and finds much deeper resonance.

Thus, if the first aspect of engagement in both countries is about telling people's own stories, in their own words, and (in the case of Kenya) their own language, the second aspect is in the form of the performance. In Kenya, this was principally about audience participation in forum theatre. In Cornwall, it revolved around people playing themselves in performance. Again, this drew people in, made them active participants, and enabled them to experience and shape the performance in important ways. An immersive performance can translate concepts that are abstract and complex (such as resilience) into tangible experience.

By translating facts into emotive experiences, the topic moves from the cognitive to the emotional sphere. Both performances engaged with emotions and dealt very explicitly with emotions, including grief and humor. The Cornwall production developed around the main theme of loss and structured the performance on five stages of grief (as proposed by Kübler-Ross 1969). It addressed the following central questions of the play: What do we find it hard to let go of? What do we lose when the sea floods and the coast is eroded? The five stages of grief explored in the 
play are: catastrophe (the event, i.e., the storm), denial, anger, sadness, and acceptance. The play was structured around these five emotional responses. It was felt that grief was really important to convey to policy makers, and when the responses to events such as extreme weather are identified as part of grief, then it is easier to understand why people do what they do and gives insights into possible approaches and responses to the questions: What can we lose? and What do we want to keep?

In particular, the actors discussed how denial was so prevalent in discussing responses to possible climate change, i.e., the issues are "too big, too difficult," and the response was often, "We've always had storms, we get on with it." Addressing denial was an aspect of the grief response that the Golden Tree team felt was open for theatre to explore, and in doing this, people recognized their own experiences and stories.

In the case of Cornwall, this approach then opened a range of further issues for discussion, especially around how to prepare people for loss, of valued places perhaps, and how to let go. Golden Tree view the theatre they do as a means of sensitization, perhaps in preparation for the (next) catastrophic event. In Kenya, humor was used as a way of connecting with people but also as a way of breaking tensions around potentially sensitive or divisive topics.

\section{Reframing resilience}

The activities reveal valuable things about what matters to people and about the role of immersive and participatory drama. Various participants referred to how the performance in Cornwall gave them a "real" experience of what flooding or coastal erosion means. In a follow-up interview, one participant, "B," summarized this point by commenting:

\section{It was different because we could have sat down and have a Power Point, and you could have demonstrated all things that you see on television, but when you're there actually experiencing it, you're sort of in the performance, because you were part of the people, weren't you; we were all part of it and being face to face with people that were losing their properties, so I thought that it was a great way to bring it home.}

Another participant from Cornwall, "R," gave an example of this sense of immersion, when talked about what it was like when she arrived at the pub.

[There was] a real sense of this is a community gathered, and you could imagine that, you know, in a real situation of crisis, that actually everyone may well gather together in the pub like that. There wouldn't really be any standing room, it would be a bit hot. The sensory experience of people gathered together with an imperative was actually quite well reflected I think. Well it was, and the sort of energy: "we don't really know what we're doing but we're all here so..."

Furthermore, as participant "L" remarked, in the case of the topic of flooding, the actual event is too gloomy and overwhelming to use as a useful reference point. However, a performance can be a colourful, more gentle way to address these issues:

There has to be something unique in how you get people to experience that [a flood event] on a regular basis but not have to wait for a storm ... or a big gloomy event. (...) what can you do to talk to people about this horrible subject but in a nice way, in a colourful way? So my coming away sort of was that this performance is brilliant, it is genius.

In contributing toward reframing resilience (Brown 2016) and pointing toward social change and transformative action, this work starts to fill the need, identified by Tschakert (2012) and O'Brien (2012), among others, for new methods and engagement by global change researchers. Such methods include "creative and engaging methodologies which ditch descriptive social vulnerabilities and replace them with approaches that allow for diagnoses drivers of inequality, marginalisation, and barriers to transformative change. At the core should be promotion of agency and resilience through processes of engagement and collective learning" (Tschakert 2012:152).

Forum theatre is derived from Boal's (1992) "Theatre of the Oppressed," and it is used to address specific issues as well as complex problems such as poverty and climate change. Its challenge is to shape these issues into manageable, problemposing plays that give participants the opportunity to move beyond conventional interventions and identify radical solutions rather than reproducing popular discourses (Snyder-Young 2011). We witnessed this at work in Kenya in several ways and in the solutions suggested by participants in the communities. The process identified some of the underlying social causes and drivers of vulnerability and how they might be overturned; for example, the need for education (particularly of girls) and livelihood diversification. It also revealed the necessity for sustainable resource management practices (fishing gear, mangrove conservation and planting) and coastal defence infrastructure (building a sea wall). However, each of these initiatives was predicated on the need for social cohesion and for government investment in the locality.

In summary, three factors are found to be of importance in devising, performing, and evaluating participatory theatre around issues of resilience: experience, emotion, and empathy. These three Es also pinpoint some of the bonuses of arts engagement; they are aspects that conventional social science research does not emphasise and, in fact, often tries to minimize in striving for "unbiased" perspectives and "representativeness" in research methods.

First, that the performance is experiential in that it tells the story of the participants, not the researchers. It is about their lives and their place, and this is critical in making the story real, relevant, salient, and interesting. This also adds to current discussions of the need for more analyses of subjective or experiential resilience (Jones and Tanner 2015, Brown 2016).

Second, emotional engagement with the topic, using grief in the case of Cornwall and humor in Kenya, connects with the audience and brings new dimensions to understanding how people respond to shocks. A body of literature is emerging that emphasizes emotions as intrinsically important in terms of methods of engagement and participatory research (e.g., Tschakert et al. 2013, Ryan 2016), as well as a critical but poorly acknowledged aspect of climate change impacts (Adger et al. 2013).

Third, empathy, putting oneself in another's shoes, plays an important part in understanding how people respond to events 
and in identifying what we share rather than emphasizing our differences. The emotional connection we made in the performances enabled the emergence of empathic dialogues, similar to how Heras and Tàbara (2016) identify that theatre can provide new opportunities for empathic dialogues, and ultimately facilitated the discussion of cross-cultural experiences. This facilitation at once acknowledged and gave credibility and weight to people's experiences and emotional responses.

The importance of this engagement and its potential for transformative change is reflected in participant " $R$ 's" comments after the Porthleven performance.

Our approach of using technology and the rational paradigm, it doesn't actually generate motivated responses because it happens up here [she points at her head] and not in there. [points at her heart] So I think it is so important that we start dropping it down to there; so to do that, it is really important that we collaborate with those people [creative practitioners] because they are experienced practitioners of creating change here [points at her heart again].

\section{CONCLUSIONS}

Here, we explored and exemplified the potential of participatory drama to open up new spaces to explore the lived experiences, imaginations, emotions, and possible solutions around global change required for transformative action, and how (as Hawkins et al. 2015 suggest) art might provide a means of expanding the social in reflecting on social ecological transformations and futures. Clearly, the creative arts can play many important roles in research and practice in the resilience field. Our project, "You, me, and our resilience" has aimed to move beyond applying art as a communications approach to codesigning and codeveloping participatory theatre to explore resilience in two very different coastal contexts. Our reflections on this process suggest that such an approach adds to our understanding of resilience and, in its own way, may contribute toward building resilience of the communities with whom we work. Where does this take us as researchers? First, it emphasizes our responsibilities as researchers and collaborators to provide feedback to communities and to support them in finding ways to address the problems and solutions they have identified through their engagement with the process of creating and participating. Second, it exposes our responsibility to amplify and to communicate those voices to the privileged fields and networks that we can access.

Responses to this article can be read online at: http://www.ecologyandsociety.org/issues/responses. $\mathrm{php} / 9145$

\section{Acknowledgments:}

This research and PI Brown are the beneficiaries of a financial contribution from $A X A$ Research Fund for the project "AXA Outlook Climate Change and Resilience." We are very grateful to the AXA Research Fund for its support for this work. We thank the members of S.A.F.E. Pwani and Golden Tree Productions who worked on the project and on the described activities. We are most grateful to the communities in Kenya and Cornwall who worked alongside the teams and who gave us the chance to learn from them and with them during the production and performances of Gangavasi and Weather the Storm.

\section{LITERATURE CITED}

Adams, C. 2002. Environmental art: a brief introduction. Centre for Contemporary Art and the Natural World, Exeter, UK.

Adger, W. N. 2000. Social and ecological resilience: are they related? Progress in Human Geography 24(3):347-364. http://dx. doi.org/10.1191/030913200701540465

Adger, W. N., J. Barnett, K. Brown, N. Marshall, and K. O’Brien. 2013. Cultural dimensions of climate change impacts and adaptation. Nature Climate Change 3(2):112-117. http://dx.doi. org/10.1038/nclimate1666

Arons, W., and T. J. May. 2012. Introduction. Pages 1-10 in W. Arons and T. J. May, editors. Readings in performance and ecology. Palgrave Macmillian, New York, New York, USA. http://dx.doi. org/10.1057/9781137011695

Berkes, F., and H. Ross. 2013. Community resilience: toward an integrated approach. Society and Natural Resources 26(1):5-20. http://dx.doi.org/10.1080/08941920.2012.736605

Berleant, A., editor. 2002. Environment and the arts: perspectives on environmental aesthetics. Ashgate, Farnham, UK.

Bishop, C. 2012. Artificial hells: participatory art and the politics of spectatorship. Verso, London, UK.

Boal, A. 1992. Games for actors and non-actors. Routledge, New York, New York, USA.

Boon, R., and J. Plastow, editors. 2004. Theatre and empowerment: community drama on the world stage. Cambridge University Press, Cambridge, UK. http://dx.doi.org/10.1017/cbo9780511486166

Brown, K. 2016. Resilience, development and global change. Routledge, London, UK.

Brown, K., and E. Westaway. 2011. Agency, capacity, and resilience to environmental change: lessons from human development, well-being, and disasters. Annual Review of Environment and Resources 36:321-332. http://dx.doi.org/10.1146/ annurev-environ-052610-092905

Cherry, N. L. 2005. Preparing for practice in the age of complexity. Higher Education Research and Development 24(4):309-320. http://dx.doi.org/10.1080/07294360500284649

Cinner, J. E., T. R. McClanahan, N. A. J. Graham, T. M. Daw, J. Maina, S. M. Stead, A. Wamukota, K. Brown, and Ö. Bodin. 2012. Vulnerability of coastal communities to key impacts of climate change on coral reef fisheries. Global Environmental Change 22(1):12-20. http://dx.doi.org/10.1016/j.gloenvcha.2011.09.018

Eakin, H. C., M. C. Lemos, and D. R. Nelson. 2014. Differentiating capacities as a means to sustainable climate change adaptation. Global Environmental Change 27:1-8. http:// dx.doi.org/10.1016/j.gloenvcha.2014.04.013

Ede, S. 2005. Art and science. I. B. Tauris, London, UK. 
Funtowicz, S. O., and J. R. Ravetz. 1993. Science for the postnormal age. Futures 25(7):739-755. http://dx.doi.org/10.1016/0016-3287 (93)90022-1

Gray, D., L. Colucci-Gray, and E. Camino, editors. 2011. Science, society and sustainability: education and empowerment for an uncertain world. Routledge, London, UK.

Hawkins, H., S. A. Marston, M. Ingram, and E. Straughan. 2015. The art of socioecological transformation. Annals of the Association of American Geographers 105(2):331-341. http://dx. doi.org/10.1080/00045608.2014.988103

Heras, M., and J. D. Tàbara. 2014. Let's play transformations! Performative methods for sustainability. Sustainability Science 9 (3):379-398. http://dx.doi.org/10.1007/s11625-014-0245-9

Heras, M., and J. D. Tàbara. 2016. Conservation theatre: mirroring experiences and performing stories in community management of natural resources. Society and Natural Resources 29(8):948-964. http://dx.doi.org/10.1080/08941920.2015.1095375

Jones, L., and T. Tanner. 2015. Measuring 'subjective resilience': using people's perceptions to quantify household resilience. ODI Working Paper 423. Overseas Development Institute, London, UK. [online] URL: https://www.odi.org/publications/9631measuring-subjective-resilience-using-peoples-perceptions-quantifyhousehold-resilience

Kübler-Ross, E. 1969. On death and dying. Routledge, London, UK.

Law, J. 2004. After method: mess in social science research. Routledge, London, UK.

O'Brien, K. 2012. Global environmental change II: from adaptation to deliberate transformation. Progress in Human Geography 36(5):667-676. https://doi.org/10.1177/0309132511425767

Pearson, M. 2010. Site-specific performance. Palgrave Macmillian New York, New York, USA.

Ryan, K. 2016. Incorporating emotional geography into climate change research: a case study in Londonderry, Vermont, USA. Emotion, Space and Society 19:5-12. http://dx.doi.org/10.1016/j. emospa.2016.02.006

Seeley, C., and P. Reason. 2008. Expressions of energy: an epistemology of presentational knowing. Pages 25-46 in $\mathrm{P}$. Liamputtong and J. Rumbold, editors. Knowing differently: artsbased and collaborative research methods. Nova Science, New York, New York, USA.

Snyder-Young, D. 2011. Rehearsals for revolution? Theatre of the Oppressed, dominant discourses, and democratic tensions. Research in Drama Education: the Journal of Applied Theatre and Performance 16(1):29-45. http://dx.doi.org/10.1080/13569783.2011.541600

Szerszynski, B. 2003. Technology, performance and life itself: Hannah Arendt and the fate of nature. Sociological Review 52 (S2):203-218. https://doi.org/10.1111/j.1467-954X.2004.00459.X

Szerszynski, B., W. Heim, and C. Waterton. 2003. Introduction. Sociological Review 52(S2):1-14. https://doi.org/10.1111/ j.1467-954X.2004.00447.X
Tschakert, P. 2012. From impacts to embodied experiences: tracing political ecology in climate change research. Geografisk Tidsskrift-Danish Journal of Geography 112(2):144-158. http://dx. doi.org/10.1080/00167223.2012.741889

Tschakert, P., R. Tutu, and A. Alcaro. 2013. Embodied experiences of environmental and climatic changes in landscapes of everyday life in Ghana. Emotion, Space and Society 7:13-25. http://dx.doi.org/10.1016/j.emospa.2011.11.001

Van Erven, E. 2001. Community theatre: global perspectives. Routledge, London, UK.

Wilkie, F. 2002. Mapping the terrain: a survey of site-specific performance in Britain. New Theatre Quarterly18(2):140-160. https://doi.org/10.1017/S0266464X02000234 